ARTICLE

\title{
Bark-dwelling methanotrophic bacteria decrease methane emissions from trees
}

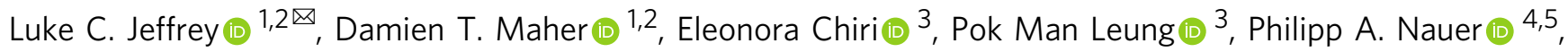
Stefan K. Arndt (1) ${ }^{5}$, Douglas R. Tait (1) ${ }^{1,2}$, Chris Greening (10 ${ }^{3}$ \& Scott G. Johnston (1) ${ }^{1,2}$

Tree stems are an important and unconstrained source of methane, yet it is uncertain whether internal microbial controls (i.e. methanotrophy) within tree bark may reduce methane emissions. Here we demonstrate that unique microbial communities dominated by methaneoxidising bacteria (MOB) dwell within bark of Melaleuca quinquenervia, a common, invasive and globally distributed lowland species. In laboratory incubations, methane-inoculated M. quinquenervia bark mediated methane consumption (up to $96.3 \mu \mathrm{mol} \mathrm{m} \mathrm{m}^{-2}$ bark $\mathrm{d}^{-1}$ ) and reveal distinct isotopic $\delta^{13} \mathrm{C}-\mathrm{CH}_{4}$ enrichment characteristic of $\mathrm{MOB}$. Molecular analysis indicates unique microbial communities reside within the bark, with MOB primarily from the genus Methylomonas comprising up to $25 \%$ of the total microbial community. Methanotroph abundance was linearly correlated to methane uptake rates $\left(R^{2}=0.76, p=0.006\right)$. Finally, field-based methane oxidation inhibition experiments demonstrate that bark-dwelling MOB reduce methane emissions by $36 \pm 5 \%$. These multiple complementary lines of evidence indicate that bark-dwelling $\mathrm{MOB}$ represent a potentially significant methane sink, and an important frontier for further research.

\footnotetext{
${ }^{1}$ Southern Cross Geoscience, Southern Cross University, Lismore, NSW, Australia. ${ }^{2}$ Faculty of Science and Engineering, Southern Cross University, Lismore, NSW Australia. ${ }^{3}$ Department of Microbiology, Biomedicine Discovery Institute, Monash University, Clayton, VIC, Australia. ${ }^{4}$ School of Chemistry, Monash University, Clayton, VIC, Australia. ${ }^{5}$ School of Ecosystem and Forest Sciences, University of Melbourne, Richmond, VIC, Australia. ${ }^{\circledR}$ email: luke.jeffrey@scu.edu.au
} 
M ethane $\left(\mathrm{CH}_{4}\right)$ is $\sim 32$ to 87 times more potent than carbon dioxide at warming the Earth's atmosphere ${ }^{1}$ Methane emissions from tree stems has received growing attention and is considered a new frontier in the global carbon cycle ${ }^{2-6}$. With an estimated three trillion trees on Earth and reforestation/afforestation promoted as viable climate change mitigation strategies ${ }^{8-11}$, a mechanistic understanding of the processes driving and moderating methane emission from trees is of critical importance. Freshwater wetland trees typically emit much higher rates of methane $5^{5,12,13}$ than their mangrove ${ }^{14}$ and upland forest counterparts ${ }^{15-19}$. This is because the poorly drained, carbon-rich soils typical of freshwater wetland forests are favourable for methanogenesis. Recent research revealed that lowland trees contributed $\sim 50 \%$ of the Amazon methane emission budget $^{5}$, highlighting the potential importance of this emission pathway. However, a lack of data on tree-mediated methane emissions has prevented their inclusion in global methane budgets ${ }^{4}$.

Methane-oxidising bacteria (MOB) can decrease methane emissions in a wide range of natural environments. Wetlands are recognised as Earth's largest natural source of atmospheric methane $e^{4,20}$, yet $50-90 \%$ of the methane produced within wetlands may be oxidised before reaching the atmosphere ${ }^{21-23}$. Although the importance of MOB within wetland soil and water is well documented ${ }^{23-28}$, their possible role within trees has yet to be characterised. Methanogenic archaea have been identified within the heartwood and sapwood of several lowland tree species $^{29-32}$, but the operational taxonomic units of methanotrophic families were exceedingly rare $^{30}$ and their influence on tree stem methane emissions remains unquantified. Until now, it is unclear if bark may provide a habitat for MOB.

Here, we establish that tree stem bark can host previously uncharacterised microbiomes and unique MOB communities that substantially mitigate tree stem methane emissions and thereby help regulate Earth's climate. Our study combined the use carbon stable isotope analysis $24,28,33,34$, in situ methanotrophy inhibitors $^{35,36}$ and molecular community profiling ${ }^{37,38}$, which have each been previously used to determine the rates and mediators of microbial oxidation in wetlands and other environments. On this basis, we provide multiple lines of biogeochemical and microbial evidence that abundant MOB occupy tree bark and represent an uncharacterised methane sink.

\section{Results and discussion}

Methane oxidation potential and fractionation during bark incubations. In order to detect MOB activity, we monitored methane concentrations and isotope fractionation in methaneinoculated gas-tight bottles containing freshly collected Melaleuca quinquenervia bark samples from three different sites (see Supplementary Methods). Because the heavier ${ }^{13} \mathrm{C}-\mathrm{CH}_{4}$ isotope contains slightly stronger bonds, $\mathrm{MOB}$ preferentially consume ${ }^{12} \mathrm{C}-\mathrm{CH}_{4}$, thereby triggering isotopic fractionation. Two laboratory time series experiments both revealed clear methane consumption coupled to $\delta^{13} \mathrm{C}-\mathrm{CH}_{4}$ enrichment (Fig. 1). There was considerable variation in methane oxidation rates between sampled trees of the second experiment, with methane uptake ranging from 3.0 to $81.2 \mu \mathrm{mol} \mathrm{m}^{-2}$ bark d ${ }^{-1}$ (Supplementary Table 1) or 16 to $882 \mu \mathrm{g}$ per $\mathrm{kg}$ of bark $\mathrm{d}^{-1}$. No methane consumption or fractionation occurred within blank controls and sterilised (microwaved) bark treatments (Fig. 1). The average fractionation factor $(\alpha)$ observed between the bark samples was similar across the three sampled sites (MF1: $1.040 \pm 0.013$; FF1: $1.031 \pm 0.005$; FF2: $1.033 \pm 0.017$; Fig. 1 and Supplementary Table 1). Fractionation factors were generally higher than reported literature values for $\mathrm{MOB}$, including those reported for upland temperate forested soils $(\alpha=1.018-1.022)^{39,40}$ and tropical forested soils $(1.012-1.023)^{41}$, but were within range of both subtropical wetlands $(\alpha=1.003-1.032)^{24,42}$ and rice paddies $(\alpha=1.013-1.033)^{43,44}$ (Supplementary Table 2). Our lab-based fractionation factor a values may be higher due to methane inoculation concentrations differing to natural field conditions ${ }^{45}$ or may reflect the relatively high community abundance of barkdwelling MOB found in paired samples (see microbial data in Fig. 2).

Methane oxidation is strongly correlated with MOB abundance in tree bark. Molecular analysis was used to determine the abundance (quantitative PCR) and composition (amplicon sequencing) of the total bacterial communities (via universal $16 \mathrm{~S}$ rRNA gene) and MOB communities (via pmoA gene encoding a particulate methane monooxygenase subunit) within lower stem bark samples $(n=14)$. The marker gene for aerobic methanotrophy $(p m o A)$ was detected in relatively high abundance in every sample (av. $2 \times 10^{9}$ copies per gram of dry sample material; range of $4 \times 10^{7}$ to $5 \times 10^{9}$; Fig. $2 \mathrm{a}$ ), with values comparable to wetland sediments ${ }^{46}$. The relative abundance of MOB was remarkably high within the bark microbial communities (5.4 to $24.7 \%$ based on qPCR, Fig. $2 \mathrm{c} ; 3.2$ to $12.8 \%$ based on amplicon sequencing, Fig. 2d). This is in stark contrast to the reported low MOB abundance in the heartwood and sapwood of other tree species $(<0.1 \% \text {, Populus deltoides })^{30}$. Compositional profiling revealed that the bark samples hosted unique microbial communities that were distinct from those in adjacent sediments and waters (Fig. 2b and Supplementary Fig. 2; $p<0.001$ ) and likely adapted to the acidic $\mathrm{pH}$ observed in the bark ${ }^{47}$. Over half of the total bacterial community comprised five genera, Mycobacterium, Acidocella, Occallatibacter, Conexibacter and the MOB genus Methylomonas (Fig. 2f and Supplementary Fig. 2). Consistently, Methylomonas accounted for the majority of the methanotrophic community based on analysis of the total bacterial community (Fig. 2e) and MOB community (Supplementary Fig. 3). Other acidophilic members of the genus are known to be associated with Sphagnum mosses and have been shown to significantly mitigate methane emissions from wetlands ${ }^{38,47}$, suggesting Methylomonas are well-adapted to vegetation-associated lifestyles. Several trees also hosted a large proportion of novel lineages of Methylacidiphilaceae, a family of acidophilic methanotrophs from the phylum Verrucomicrobia ${ }^{48-50}$ (Fig. 2e), potentially expanding the tree MOB niche to two phyla. Remarkably, MOB abundance determined by qPCR and $16 \mathrm{~S}$ rRNA amplicon sequencing strongly predicted methane oxidation rates with paired bark samples (T1-T7) from FF2 $\left(R^{2}=0.76\right.$ and 0.74 , respectively; Fig. 2c, d). Thus, tree-bark methane oxidation rates are wellexplained by the high yet variable abundance of bark-associated methanotrophs dominated by the genus Methylomonas (Fig. 2e).

Field-based MOB inhibition confirms methane sink activity within bark. To both confirm and quantify the MOB activity moderating tree stem methane emissions in situ, we utilised DFM inhibition experiments on $M$. quinquenervia lower stems $(n=88)$. The use of specific inhibitors of methanotrophy enable estimation of methane oxidation rates by MOB under both laband field-based conditions ${ }^{35,36,51,52}$. Low concentrations of difluoromethane $\left(\mathrm{CH}_{2} \mathrm{~F}_{2} ; \mathrm{DFM}\right)$ temporarily and effectively inhibit methanotrophy by competing with methane as a substrate for methane monooxygenase ${ }^{36,53}$ (the major enzyme catalysing aerobic methane oxidation) without affecting methanogenesis ${ }^{35}$. To achieve this, replicate baseline tree stem methane fluxes were measured before (Supplementary Fig. 1a) and then $\sim 1 \mathrm{~h}$ after the addition of DFM (Supplementary Fig. 1b) into tree flux 

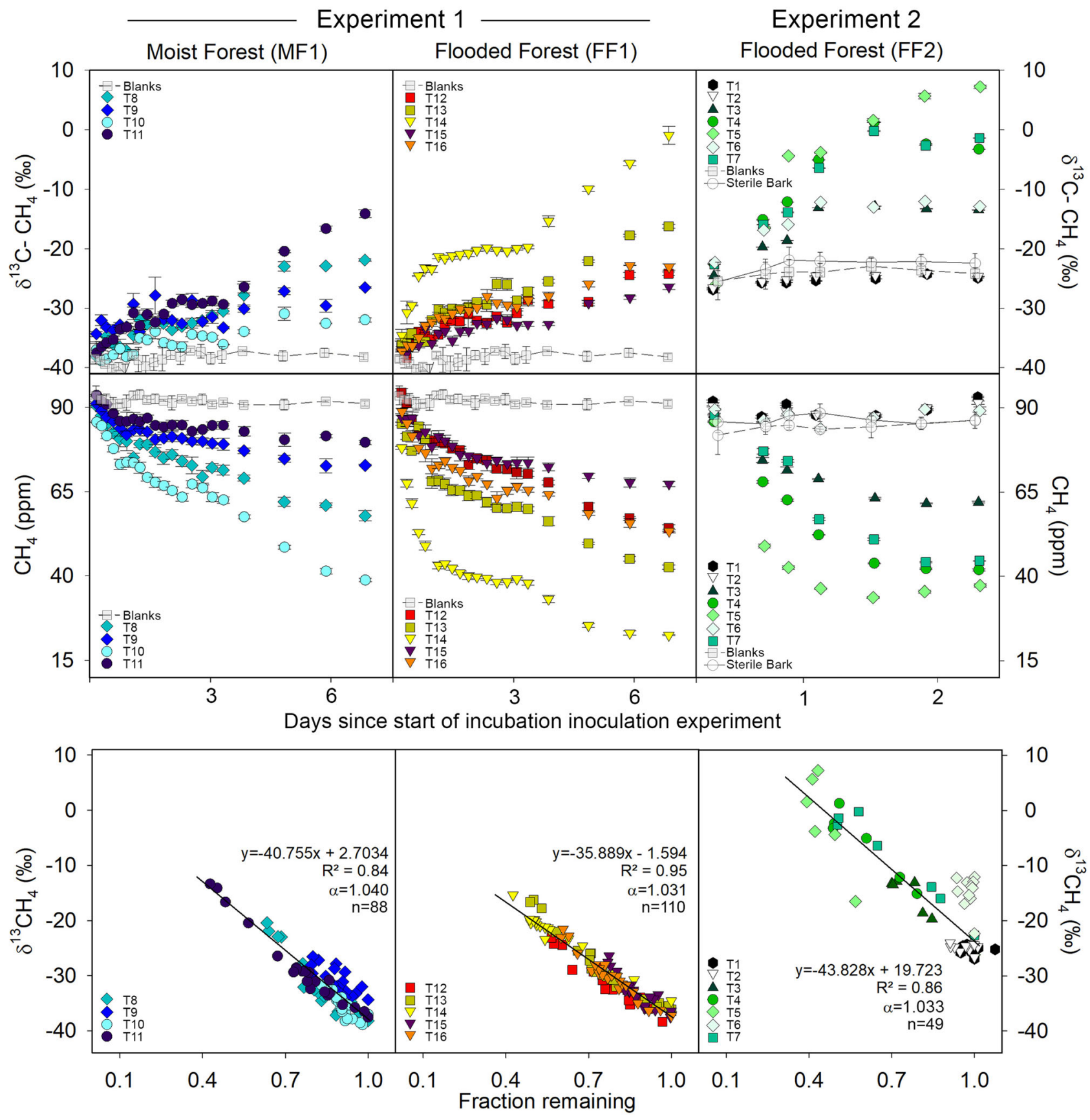

Fig. 1 Methane oxidising bacteria (MOB) time series incubation experiments of methane-inoculated M. quinquenervia bark. The panels depict oxidation as $\delta^{13} \mathrm{C}-\mathrm{CH}_{4}$ enrichment vs time (top), decrease in methane concentration (ppm) vs time (middle) and the $\delta^{13} \mathrm{C}-\mathrm{CH}_{4}$ vs fraction remaining (bottom). Note: Different $\delta^{13} \mathrm{C}_{-} \mathrm{CH}_{4}(\% o)$ starting values between the first (MF, FF1) and second (FF2) experiments are due to using a different methane gas standard. Coloured symbols represent each bark sample (see Supplementary Table 1, T = tree), error bars are \pm SD and $\alpha=$ fractionation factor. Average values for both controls (blank bottles and sterilised bark) are shown as grey symbols with trend line. Note: T1, T2 and T6 were removed from fraction remaining correlation due to lack of $\mathrm{MOB}$ oxidation, which was supported by lower MOB abundance within the paired bark samples (see microbial data in Fig. 2). Fraction remaining is the proportion of methane not oxidised by $M O B$ during the time series.

chambers $^{34}$ (see Supplementary Methods for more information). A net positive change in methane fluxes was observed in nearly all chambers after the addition of DFM (average increase of $36.3 \pm$ $5.4 \%)$, indicating $\mathrm{MOB}$ were present, active and effectively inhibited (Fig. 3). The changes in blank (control) repeated chamber measurements $(n=39)$, without the addition of DFM over a similar incubation period, were normally distributed around zero (mean of $3.1 \pm 2.5 \%$ ) and significantly different to the MOB inhibited DFM measurements $(p<0.001$, Fig. 3$)$. The change in methane flux rates ranged between -55 to $187 \%$ and -36 to $35 \%$ for the DFM and control experiments respectively. In some cases, outlier values (both positive and negative) were at locations of lowest methane fluxes, which are most sensitive to subtle variability. Although environmental conditions were relatively stable during all DFM experiments (Supplementary Table 3) and each measurement completed within $\sim 1 \mathrm{~h}$, we cannot rule out that some temporal variability of both methane oxidation and production may occur. Overall, these results 

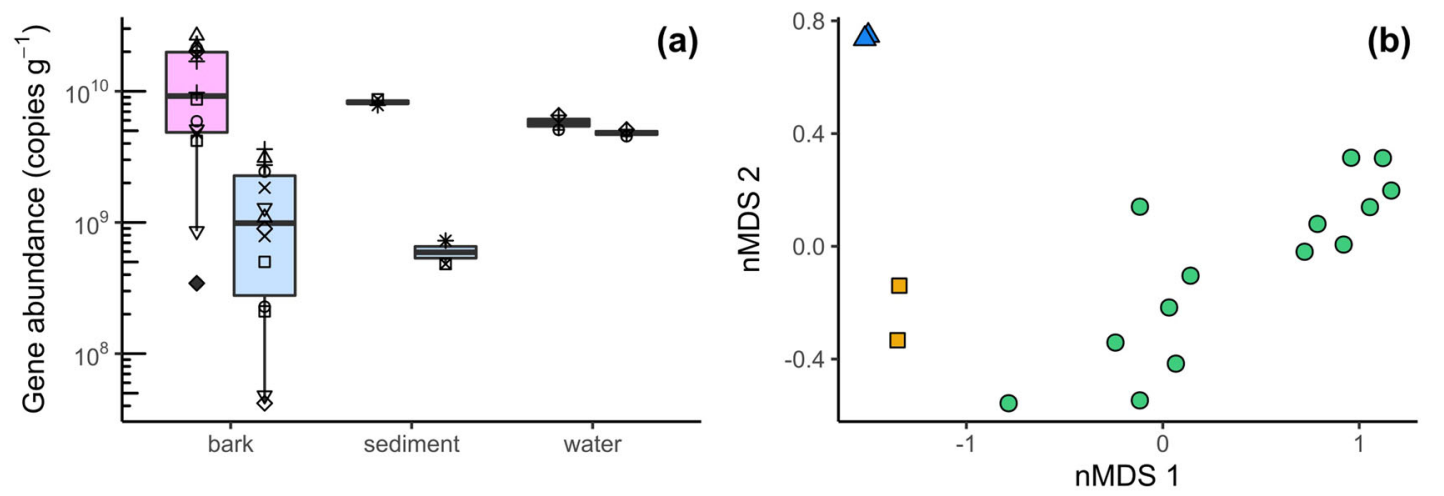

Gene

16S rRNA

曰 $p m o A$

Sample type

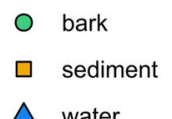

$\triangle$ water
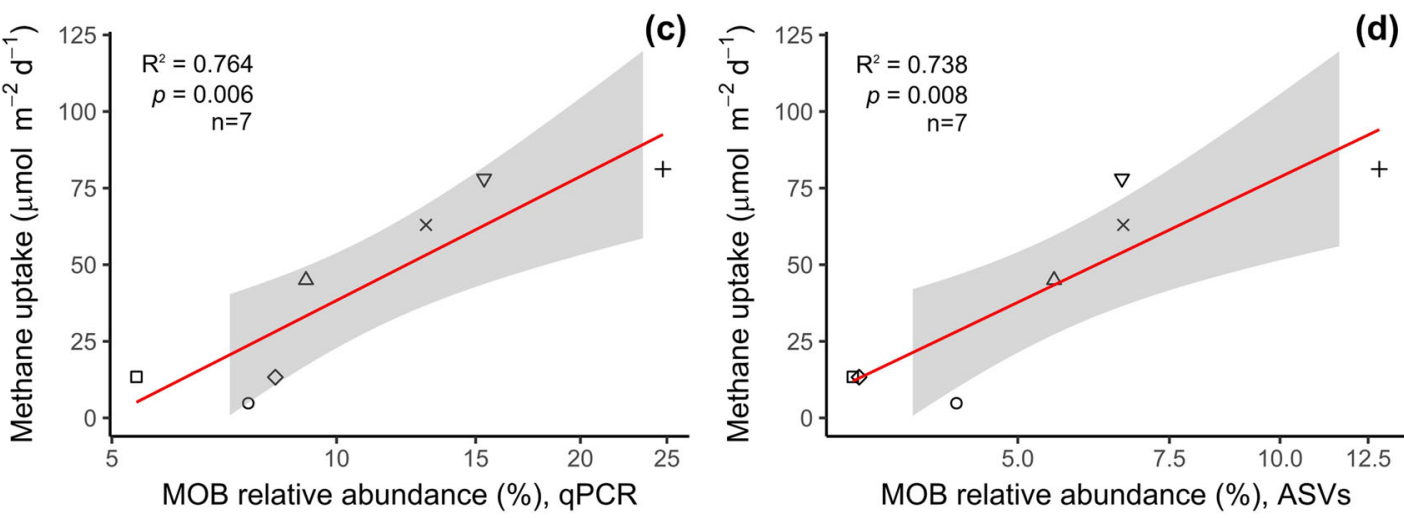

Sample

(e)
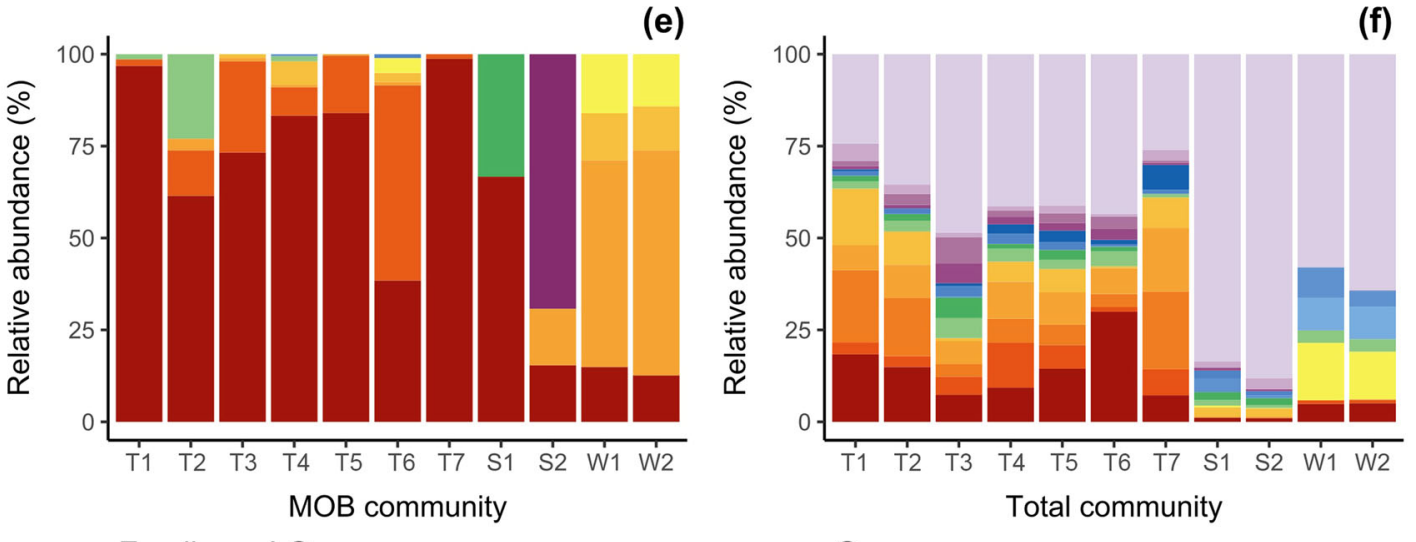

Family and Genus

\section{Genus}
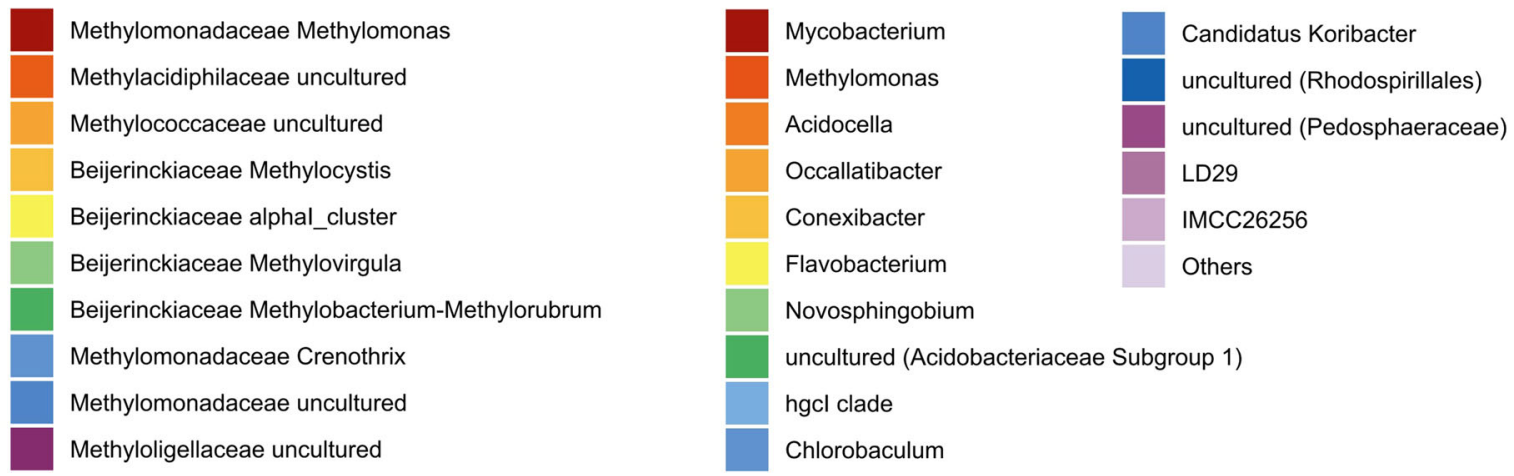

provide a first order estimate of in situ bark dwelling $\mathrm{MOB}$ activity mitigating $\sim 36 \%$ of the methane emissions from M. quinquenervia tree stems.

Future frontiers. Overall, this study provides conclusive evidence of active methane oxidation by a unique MOB community within the bark of a widely distributed lowland tree species. This important discovery adds to our evolving understanding of tree mediated methane fluxes. If $\mathrm{MOB}$ are a ubiquitous feature within the bark of methane emitting trees, our conceptual understanding of the global methane cycle may need revision. However, as the $M$. quinquenervia bark structure represents an ideal methane transport medium ${ }^{12}$ and a potentially unique habitat for $\mathrm{MOB}$ communities, further work on a variety of tree species featuring more common dense and woody bark substrates is required to 
Fig. 2 Summary of abundance, composition and structure of total microbial and methanotroph (MOB) communities in M. quinquenervia bark ( $n=14$, $\mathbf{T}=$ tree), sediment sample $(\boldsymbol{n}=\mathbf{2}, \mathbf{S}=$ sediment) and water samples $(\boldsymbol{n}=\mathbf{2}, \mathbf{W}=$ water $)$. a Abundance determined by quantitative PCR of the total microbial community (universal $16 \mathrm{~S}$ rRNA gene copy number) and of the MOB community (pmoA gene copy number). Box plots depict medians, lower and upper quartiles and maximum and minimum values. $\mathbf{b}$ Non-metric multidimensional scaling (nMDS) ordination of the MOB community structure (beta diversity) measured by Bray-Curtis distance matrix of the $16 \mathrm{~S}$ rRNA gene amplicon sequences affiliated with known methanotrophic families and genera. c, $\mathbf{d}$ Correlation between laboratory incubation measurements of the first $24 \mathrm{~h}$ of methane uptake from bark samples (Supplementary Table 1) and logittransformed $\mathrm{MOB}$ community proportion in the total community (percentage of MOB relative abundance) inferred from qPCR (c) and $16 \mathrm{~S} r \mathrm{RNA}$ amplicon sequence variants (d) (linear regression and $t$ test; $n=7 ; \mathrm{df}=6$; the grey area indicates $95 \%$ confidence interval) e Relative abundance of methanotrophic genera identified from the analysis of the $16 \mathrm{~S}$ rRNA gene amplicon sequences. In the case of uncultured genera, taxonomic resolution according to family is reported. $\mathbf{f}$ Relative abundance of $16 \mathrm{~S}$ rRNA gene amplicon sequences resolved at the taxonomic level of genus.

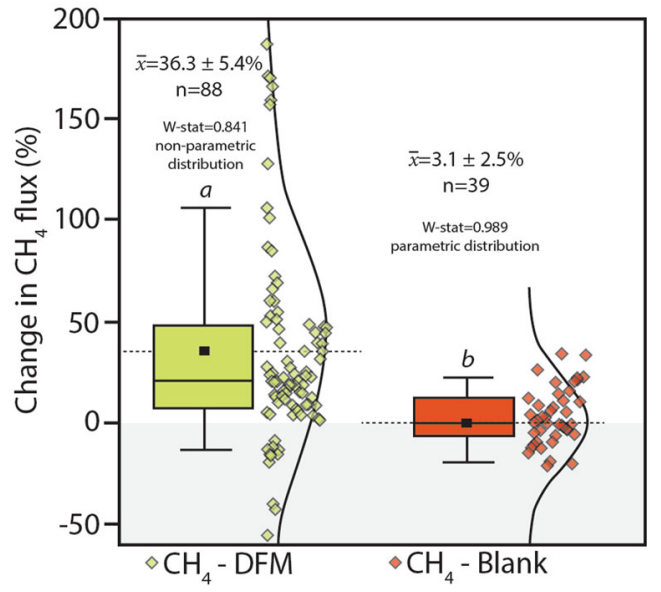

Fig. 3 Summary of in situ methanotroph (MOB) inhibitor tests conducted using difluoromethane (DFM) on $M$. quinquenervia bark revealing the mostly positive $\%$ increase in methane fluxes $\sim \mathrm{h}$ after the addition of DFM and non-parametric distribution (Shapiro-Wilk, $\boldsymbol{W}$-stat $=\mathbf{0 . 8 4 1}$ ).

The blank replicates (i.e. repeated chamber measurements after $\sim \mathrm{h}$, but no DFM addition) showed no change in mean methane fluxes $(3.1 \pm 2.5 \%)$ and normal distribution (Shapiro-Wilk, $W$-stat $=0.989$ ). There were significant differences between treatments $a$ and $b$ (ANOVA on-ranks, $p<0.001$ ). Note: The box represents the 25-75 percentile, error bars 1-99 percentile, the solid horizontal line is the median, dashed line and small square $=$ mean $(\bar{x})$ and the curved line and scatter plots show the data distribution.

determine the generalisability of these findings. Future work in this frontier research area should also focus on (i) constraining $\mathrm{MOB}$ importance and magnitude of MOB in mitigating methane emissions from trees, (ii) investigating $\mathrm{MOB}$ ecophysiology through metagenomic, imaging and cultivation studies and (iii) determining MOB spatial and geographical distribution from tree scale to global scale, respectively.

\section{Methods}

In situ tree stem methane flux rates and bark preparation. M. quinquenervia lower stem fluxes from forests in subtropical north-eastern New South Wales (NSW), Australia were determined using a small chamber directly attached to the tree and connected with a portable cavity ring-down spectrometer (CRDS, G4301GasScouter, Picarro) using the 'Small Nimble In situ Fine-scale Flux' (S.N.I.F.F.) method ${ }^{34}$. Briefly, a small $50 \mathrm{~mm}$ wide PVC chamber was attached to tree stems using white potting clay to create an airtight seal with the stem surface. The SNIFF stem chamber was then connected to the CRDS inlet using a $2 \mathrm{~m}$ length of gas tubing (Bev-A-line IV ${ }^{\mathrm{TM}}$ ) via a drying agent (Drierite), with the gas stream then returned from the CRDS outlet to the SNIFF chamber, to close the loop. After 2 min incubations, the $\mathrm{CH}_{4}$ flux rate (ppm sec${ }^{-1}$ ) was converted to an areal $\mathrm{CH}_{4}$ flux $\left(\mathrm{mmol} \mathrm{m}^{-2} \mathrm{~d}^{-1}\right)$ using the flux equation:

$$
F=\left[s\left(V / R T_{\text {air }} A\right)\right] t
$$

where $s$ is the regression slope ( $\left.\mathrm{ppm} \mathrm{s}^{-1}\right), V$ is the closed loop volume $\left(\mathrm{m}^{3}\right), R$ is the universal gas constant $\left(8.205 \times 10^{-5} \mathrm{~m}^{3} \mathrm{~atm} \mathrm{~K}^{-1} \mathrm{~mol}^{-1}\right)$ and $T_{\text {air }}$ is the air temperature inside the chamber $(\mathrm{K}), A$ is the measured surface area of the clay ring after each measurement $\left(\mathrm{m}^{2}\right)$ and $t$ is the conversion from seconds to days.
During the first stable isotope MOB laboratory experiment, two bark samples were collected from lower stem heights from opposite sides of four $M$. quinquenervia trees with high methane fluxes, spanning two sites with differing hydrological characteristics (Supplementary Table 1). One site featured moist sediments (MF1) around the tree base (T8-T11, $n=4)$ whereas the other (FF1) was completely inundated with freshwater $\sim 50 \mathrm{~cm}$ up the tree stem (T12-T16, $n=5$ ). Samples T15 and T16 were paired samples collected from the same tree on the same side (Supplementary Table 1). The bark swatches were cut using a sterile razor to include all layers from the outer bark to the heartwood surface. The average depth of bark sample collected was $1.3 \pm 0.1 \mathrm{~cm}$ and ranged from 0.8 to $1.9 \mathrm{~cm}$. Within $1 \mathrm{~h}$ of bark sample collection, each sample was weighed (with samples ranging from 81 to $147 \mathrm{~g}$; Supplementary Table 1) and then volumetrically measured with a ruler $\left(\mathrm{cm}^{3}\right)$. The bark samples were then cut into sufficiently narrow strips $(\sim 1 \mathrm{~cm})$ to fit through the bottle-neck of sterile (autoclaved) $550 \mathrm{~mL}$ crimp top glass bottles. Care was taken to ensure minimal disturbance to the planar bark layers to preserve as much of the natural bark microstructure as possible. Each bottle was then capped, wrapped in aluminium foil and injected with $101 \mathrm{ppm} \mathrm{CH}_{4}$ in air gas standard (complete composition $=101 \mathrm{ppm} \mathrm{CH}_{4}, 21 \% \mathrm{O}_{2}$, balance $\mathrm{N}_{2}$; CoreGas). This was achieved by flushing each bottle for $6 \mathrm{~min}$ using a two-syringe system, featuring a long inlet syringe reaching near the bottom of the bottle and a short venting syringe evacuating the headspace closer to the top of each bottle. Four bark-free empty bottles (blanks) were used as controls, and were also wrapped, crimped and flushed using the same $101 \mathrm{ppm} \mathrm{CH}_{4}$ standard and methods.

A repeat experiment (FF2), focused solely on an inundated forest site, utilised seven trees spanning a range in $\mathrm{CH}_{4}$ flux rates $\left(1.1\right.$ to $\left.393 \mathrm{mmol} \mathrm{m}^{-2} \mathrm{~d}^{-1}\right)$ (Supplementary Table 1). Larger bark samples $(\sim 13 \times 25 \mathrm{~cm})$, collected from the lower stem of trees (Supplementary Table 1) in standing water that was on average $54.0 \pm 12.9 \mathrm{~cm}$ deep, were extracted using sterile methods and then cut into thirds. For the microbial analysis, one third of each bark sample was field-wrapped in sterile foil pockets (pre-baked at $180^{\circ} \mathrm{C}$ for $6 \mathrm{~h}$ ) immediately after extraction, and then placed on ice $(n=7)$. Ancillary sediment and surface water samples were also collected using sterile methods. The composite homogenised sediment samples $(n=2)$ were extracted from various depths of two freshly dug holes (to $20 \mathrm{~cm}$ depth), located at the edge of the wetland and within $<9.0 \mathrm{~m}$ proximity of all sampled trees. Composite homogenised water samples $(n=2)$ were collected directly from $10 \mathrm{~cm}$ below the water surface using sterile syringes from several locations nearby the inundated trees at undisturbed sites. All samples were refrigerated within $2 \mathrm{~h}$ of collection at $4{ }^{\circ} \mathrm{C}$. They were later transported with dry ice to Monash University (Greening Lab) for the microbial analysis. One third of each bark sample was prepared as per first experiment methods $(n=7)$ and were placed into sealed crimp top sterile bottles. The final third of bark sample from each tree were placed in sterile crimp top bottles, but microbial communities were neutralised by microwaving (1600W - LG model MS3882XRSK) for $2 \mathrm{~min}$, four times over, before sealing $(n=7)$. All paired samples (i.e. raw bark and microwaved control) were then inoculated with $101 \mathrm{ppm}$ methane as per the syringe method above.

Isotope time series inoculation experiment. The headspace concentration of $\mathrm{CH}_{4}$ and $\delta^{13} \mathrm{C}_{-} \mathrm{CH}_{4}$ of the inoculated bark bottles, the neutralised bark bottles and blanks were sampled using a CRDS with a sensitivity of $5 \mathrm{ppb}+0.05 \%$ of reading for ${ }^{12} \mathrm{C}$ and $1 \mathrm{ppb}+0.05 \%$ of reading for ${ }^{13} \mathrm{C}$ (Picarro, G2201-i). At 3 to 24 hourly intervals (increasing with experiment duration), a $60 \mathrm{~mL}$ gas sample of $101 \mathrm{ppm}$ $\mathrm{CH}_{4}$ was injected into the bottle septum using a long syringe needle, whilst simultaneously mixing and removing $60 \mathrm{~mL}$ of gas sample via a second and short syringe needle. To ensure adequate headspace mixing occurred, headspace mixing was repeated at least eight times before extracting each sample (i.e. the volume of gas mixed was greater than the headspace volume within each bottle). The extracted gas sample was then analysed directly from the syringe into the CRDS. The sample concentration of $\mathrm{CH}_{4}(\mathrm{ppm}), \delta^{13} \mathrm{C}-\mathrm{CH}_{4}(\%)$ and the associated $\pm \mathrm{SD}$ were recorded for each bottle treatment at each time interval. The $60 \mathrm{~mL}$ mixing additions of $\mathrm{CH}_{4}$ and $\delta^{13} \mathrm{C}-\mathrm{CH}_{4}(\%)$ to each bottle headspace were later accounted for via mass balance, to calculate the shift in $\mathrm{CH}_{4}$ and $\delta^{13} \mathrm{C}_{-} \mathrm{CH}_{4}(\%)$ over time The decrease in $\mathrm{CH}_{4}$ over the first $24 \mathrm{~h}$ was converted to uptake, as a proportion of the original surface area of each bark treatment within each bottle. The 
fractionation factor $(\alpha)$ was defined as the ratio of the oxidation rate coefficients of ${ }^{12} \mathrm{CH}_{4}$ over ${ }^{13} \mathrm{CH}_{4}$, and calculated using established methods ${ }^{54}$.

Genomic DNA extraction. High-quality and amplifiable genomic DNA were extracted from all bark $(n=14)$, sediment $(n=3)$ and water $(n=6)$ samples. For each individual bark sample, 0.13 to $0.18 \mathrm{~g}$ (wet weight) of material was frozen in liquid nitrogen and immediately homogenised using a sterile pestle and mortar until a fine powder was obtained. Genomic DNA was extracted from the homogenised samples using the Synergy 2.0 Plant DNA Extraction Kit (OPS Diagnostics LLC, US), according to the manufacturer's instructions. Genomic DNA from the sediment samples $(0.25 \mathrm{~g}$ wet weight sample) and water samples $(50 \mathrm{~mL}$ sample filtered on to sterile filter papers) were extracted using the DNeasy PowerSoil Kit (Qiagen, US), according to the manufacturer's instructions. The purity and yield of the DNA extracts were verified by spectrophotometry (NanoDrop ND-1000 spectrophotometer, Nanodrop Technologies Inc., US) and quantified by fluorometry (Qubit Fluorometer, Thermo Fisher Scientific). For the DNA extraction from each type of sample, PCR-grade water was extracted as a negative control.

Quantitative PCR. Quantitative PCR assays were performed on a QuantStudio 7 Flex Real-Time PCR instrument (Thermo Fisher Scientific) in order to quantify gene copy numbers and estimate the abundance of the total microbial (16 rRNA gene copies) and $\mathrm{MOB}$ community ( $p m o A$ gene copies). Briefly, the $p m o A$ gene was amplified using the previously described degenerate primers A189f 5'-GGNG ACTGGGACTTCTGG-3' and mb661 $5^{\prime}$-CCGGMGCAACGTCYTTACC-3 $3^{\prime 55,56}$ and cycling conditions ${ }^{57}$. The primer pair was chosen for its coverage of the MOB community from environments with elevated $\mathrm{CH}_{4}$ concentrations. The V4 hypervariable region of the $16 \mathrm{~S}$ rRNA gene was amplified using the universal Earth Microbiome Project primer pairs 515FB 5'-GTGYCAGCMGCCGCGGTAA-3' and 806RB 5'-GGACTACNVGGGTWTCTAAT- $3^{\prime 58}$, as per previously described cycling condition ${ }^{59}$. The employed reaction conditions and thermal profiles of the qPCR assays have been previously described ${ }^{37}$. Amplification from different dilutions (from undiluted to 1:100 dilution in PCR-grade water) of DNA extracts was tested, and the dilution resulting in the highest yield and quality of PCR product was used for the GPCR assays. For each assay (96-well plate), duplicate serial dilutions of quantified $16 \mathrm{~S}$ rRNA gene (from Escherichia coli) or pmoA gene amplicons, (from Methylosinus trichosporium strain OB3b) were used to generate standard calibration curves. Each sample was analysed in triplicate; amplification efficiencies $(>70 \%)$ were calculated from the slopes of the calibration curves $\left(R^{2}\right.$ values $>0.97)$. No significant amplification of the blank extractions was observed in any $\mathrm{qPCR}$ assays.

Amplicon sequencing. Amplicon sequencing of the universal $16 \mathrm{~S}$ rRNA gene was used to infer the community composition of the total bacterial and archaeal community within each sample. Amplicon sequencing of the $p m o A$ gene, encoding the particulate methane monooxygenase A subunit, was also performed to gain a higher-resolution insight into the composition of the MOB community. The same primer pairs used for the quantitative PCR assays (reported above) have been employed in the amplicon sequencing of the $16 \mathrm{~S}$ rRNA and pmoA genes. Genomic DNA extracts of 14 bark, two composite sediment and two composite water samples (pooled samples), as well as the blank extraction, were subject to Illumina pairedend sequencing at the Australian Centre for Ecogenomics, University of Queensland. The resultant raw sequences from the 16 S rRNA gene amplicon sequencing were subject to quality filtering, merging, primer trimming, denoising and singleton removal using the QIIME 2 platform ${ }^{60}$. Taxonomic affiliation of the identified amplicon sequence variants (16S-ASVs) was assigned according to the GTDB taxonomy ${ }^{61}$, release $05-\mathrm{RS} 95$. For each sample, 16S-ASVs classified as 'unassigned' (av. $5.2 \%$ ), 'Eukaryota' (av. 0.04\%), 'Chloroplast' (av. 1.7\%) and 'Mitochondria' (av. $0.3 \%$ ) were excluded as being potentially derived from plant material. The final dataset accounted for 2727 16S-ASVs, with an average sequence count number per sample of 9184 (range 3657 in sample T6.2 to 14524 in sample S2). The 16S-ASVs assigned to known methanotrophic families and genera were subset to infer MOB community structure and to estimate the proportion of the $\mathrm{MOB}$ community within the total microbial community via the 16S-ASV dataset. Note that this analysis cannot detect uncultured MOB with unknown $16 \mathrm{~S}$ rRNA gene sequences. Data processing of the $p m o A$ gene amplicon sequences followed our previously published pipeline ${ }^{37,62}$, with minor modifications. All processing steps were performed in the QIIME 2 platform and, instead of assigning the raw sequences to operational taxonomic units, raw sequences were denoised using the DADA2 pipeline ${ }^{63}$, yielding 280 high-quality $p m o A$ amplicon sequence variants ( $p m o A$-ASVs). Taxonomic affiliation of the $p m o A$-ASVs was assigned by similarity with $p m o A$ sequences of a curated database ${ }^{64}$. The average sequence count number per sample was 8556; range 5026 in sample T7.1 to 14,729 in sample T5.1. Sample T6.2, with a sequence count number of 1503 , was excluded from further analyses. Note that this analysis cannot detect highly divergent $\mathrm{MOB}$ pmoA sequences, such as those from Verrucomicrobiota and Candidatus Methylomirabilota.

Microbial diversity analyses. To assess total and $\mathrm{MOB}$ community structure based on both 16S-ASV and pmoA-ASV dataset, read count normalisation and alpha and beta diversity calculations were performed with the package phyloseq v1.30 ${ }^{65}$ from the open source software Bioconductor. Chaol, Shannon and Inverse Simpson indices were computed to assess the alpha diversity of total and MOB communities, whereas beta diversity was measured using the Bray-Curtis distance matrix ${ }^{66}$ and visualised using non-parametric multidimensional scaling ordinations (nMDS). To determine whether the observed between-group distances were statistically significant, we performed permutational multivariate analysis of variance (PERMANOVA) with the software PRIMER-E v7 (PRIMER-E Ltd., Plymouth, United Kingdom). For bark samples, correlations between $p m o A$ and $16 \mathrm{~S}$ rRNA gene abundance, qPCR- and 16S-ASV-based MOB community proportion, and $\mathrm{CH}_{4}$ uptake and in situ tree stem $\mathrm{CH}_{4}$ fluxes were tested for significance using linear regression, after appropriate variable transformations ( $\log _{10}$ for gene abundances, logit for $\mathrm{MOB}$ community proportion) and adequate model diagnostic during which we checked for normality, independency between observations and for influential data points (via Leverage and Cook's distance plots). No data point were excluded. Correlations between qPCR- and 16S-ASV-based MOB community proportion and $\mathrm{CH}_{4}$ uptake were highly significant $(p<0.008)$.

In situ methanotroph inhibitor experiments with DFM. The DFM experiments were conducted during daytime in winter, under dry sunny conditions between the 29 June-13 August 2020. Ambient air temperature amplitude varied minimally during each sample day and across the entire sampling period, increasing by an average of $2.5 \pm 0.9^{\circ} \mathrm{C}$ between 9:00-15:00, when conducting the stem methane flux experiments (Supplementary Table 3$)^{67}$. The in situ MOB oxidation rates were estimated by first measuring duplicate lower tree stem fluxes $(<50 \mathrm{~cm}$ above the water level) using the S.N.I.F.F. method as mentioned above ${ }^{34}(n=88$ trees). Then the tree stem chamber was flushed with atmospheric air for $30 \mathrm{~s}$ or until atmospheric concentration in the chamber was attained, and $120 \mathrm{~mL}$ addition of $2 \%$ DFM was slowly injected, then sealed within each chamber and left to incubate and infiltrate the bark for $\sim 45-90 \mathrm{~min}$, similar to a sufficient time previously shown to inhibit $\mathrm{MOB}^{35}$. The chamber was then again flushed again with atmospheric air and then duplicate methane flux rates were measured. Rapid stem flux measurements were possible using $2 \mathrm{~min}$ incubations, due to the small S.N.I.F.F chamber volume, CRDS sampling frequency and the high methane emissions from the flooded forest tree stems (average flux rate linear regression $r^{2}=0.985 \pm 0.006, n=$ 88 trees). As DFM has been shown to be an effective inhibitor of aerobic methanotrophy ${ }^{36}$, the difference between initial methane fluxes and the subsequent DFM inoculated fluxes were deemed to be the effect of inhibition of $\mathrm{MOB}^{53}$. Blank repeated chamber flux measurements with no DFM injections were also performed in situ to ensure no enhancement of methane fluxes occurred, as a result of repeated chamber measurement at the same location $(n=39)$. Closed loop experiments conducted in the laboratory spanning a spectrum of methane concentrations $(1.8-400 \mathrm{ppm})$ revealed no increase in methane concentrations occurred when adding $2 \%$ DFM when using a CRDS (Picarro, GasScouter G4301). Occasionally, interference with the $\mathrm{H}_{2} \mathrm{O}$ sensor was observed, but never under field conditions when DFM was left to incubate and diffuse. Shapiro-Wilk normality tests were used to determine whether the percentage change in DFM and blank repeat $\mathrm{CH}_{4}$ flux treatments were non-parametric $(p<0.05)$ and had equal variance $(p<0.05)$, using Sigmaplot 13.0. A Kruskal-Wallis one aay analysis of variance on ranks was then used to determine whether there was a significant difference between the treatments and Dunn's method was then used to isolate the group/s that differed from the others, using pairwise multiple comparison procedures, where statistically significant differences were $p<0.001$.

Reporting Summary. Further information on research design is available in the Nature Research Reporting Summary linked to this article.

\section{Data availability}

All sequence data generated and analysed in this study have been deposited at the Sequence Read Archive database and are publicly available under BioProject accession number PRJNA669491. Taxonomic affiliation of the identified amplicon sequence variants (ASVs) was assigned using the GTDB taxonomy database release 05-RS95 (for $16 \mathrm{~S}$ rRNA), and the curated database can be found at https://doi.org/10.5880/ GFZ.5.3.2016.001 (for pmoA ASVs). The lab based MOB inoculation experiment and field based DFM MOB inhibition experiment data that support the findings of this study are available at https://data.mendeley.com/datasets/tw7g2gczwb/1.

\section{Code availability}

The $\mathrm{R}$ script used to calculate methane gas flux rates are available in https:/data. mendeley.com/datasets/x2sf762mhj/1. The diversity analysis and community profiling were determined using Phyloseq package R v1.30.1 (publicly available as part of the open-source package) and the statistical analysis of diversity sequencing data were determined using PRIMER-e version 7 software (commercially available).

Received: 19 November 2020; Accepted: 8 March 2021; Published online: 09 April 2021 


\section{References}

1. Neubauer, S. C. \& Megonigal, J. P. Moving beyond global warming potentials to quantify the climatic role of ecosystems. Ecosystems 18, 1000-1013 (2015).

2. Barba, J. et al. Methane emissions from tree stems: a new frontier in the global carbon cycle. N. Phytologist 222, 18-28 (2019).

3. Covey, K. R. \& Megonigal, J. P. Methane production and emissions in trees and forests. N. Phytologist 222, 35-51 (2019).

4. Saunois, M. et al. The global methane budget 2000-2017. Earth Syst. Sci. Data https://doi.org/10.5194/essd-2019-128 (2019).

5. Pangala, S. R. et al. Large emissions from floodplain trees close the Amazon methane budget. Nature 552, 230 (2017).

6. Machacova, K. et al. Trees as net sinks for methane $(\mathrm{CH} 4)$ and nitrous oxide (N2O) in the lowland tropical rain forest on volcanic Réunion Island. $N$. Phytologist 229, 1983-1994 (2021).

7. Crowther, T. W. et al. Mapping tree density at a global scale. Nature 525, 201 (2015).

8. Arora, V. K. \& Montenegro, A. Small temperature benefits provided by realistic afforestation efforts. Nat. Geosci. 4, 514-518 (2011).

9. Lewis, S. L., Wheeler, C. E., Mitchard, E. T. \& Koch, A. Restoring natura forests is the best way to remove atmospheric carbon. Nature 568, 25-28 (2019).

10. Griscom, B. W. et al. Natural climate solutions. Proc. Natl Acad. Sci. USA 114, 11645-11650 (2017)

11. House, J. I., Colin Prentice, I. \& Le Quere, C. Maximum impacts of future reforestation or deforestation on atmospheric CO2. Glob. Change Biol. 8 , 1047-1052 (2002)

12. Jeffrey, L. C., Maher, D. T., Tait, D. R., Euler, S. \& Johnston, S. G. Tree stem methane emissions from subtropical lowland forest (Melaleuca quinquenervia) regulated by local and seasonal hydrology. Biogeochemistry 151, 273-290 (2020)

13. Sjögersten, $\mathrm{S}$. et al. Methane emissions from tree stems in neotropical peatlands. N. Phytologist 225, 769-781 (2020).

14. Jeffrey, L. C. et al. Are methane emissions from mangrove stems a cryptic carbon loss pathway? Insights from a catastrophic forest mortality. $N$ Phytologist 224, 146-154 (2019).

15. Covey, K. R., Wood, S. A., Warren, R. J., Lee, X. \& Bradford, M. A. Elevated methane concentrations in trees of an upland forest. Geophys. Res. Lett. https://doi.org/10.1029/2012gl052361 (2012).

16. Megonigal, J. P. \& Guenther, A. B. Methane emissions from upland forest soils and vegetation. Tree Physiol. 28, 491-498 (2008).

17. Wang, Z. P. et al. Methane emissions from the trunks of living trees on upland soils. N. Phytologist 211, 429-439 (2016)

18. Welch, B., Gauci, V. \& Sayer, E. J. Tree stem bases are sources of CH4 and N2 $\mathrm{O}$ in a tropical forest on upland soil during the dry to wet season transition. Glob. Change Biol. 25, 361-372 (2018).

19. Machacova, K. et al. Pinus sylvestris as a missing source of nitrous oxide and methane in boreal forest. Sci. Rep. 6, 23410 (2016).

20. Bartlett, K. B. \& Harriss, R. C. Review and assessment of methane emissions from wetlands. Chemosphere 26, 261-320 (1993).

21. Oremland, R. S. \& Culbertson, C. W. Importance of methane-oxidizing bacteria in the methane budget as revealed by the use of a specific inhibitor. Nature 356, 421-423 (1992).

22. King, G. M. Regulation by light of methane emissions from a wetland. Nature 345, 513-515 (1990)

23. Segarra, K. et al. High rates of anaerobic methane oxidation in freshwater wetlands reduce potential atmospheric methane emissions. Nat. Commun. 6, 7477 (2015).

24. Jeffrey, L. C. et al. Wetland methane emissions dominated by plant-mediated fluxes: Contrasting emissions pathways and seasons within a shallow freshwater subtropical wetland. Limnol. Oceanogr. 64, 1895-1912 (2019).

25. Tyler, S. C., Bilek, R. S., Sass, R. L. \& Fisher, F. M. Methane oxidation and pathways of production in a Texas paddy field deduced from measurements of flux, $813 \mathrm{C}$, and $\delta \mathrm{D}$ of CH4. Glob. Biogeochem. Cycles 11, 323-348 (1997).

26. Valentine, D. L. Biogeochemistry and microbial ecology of methane oxidation in anoxic environments: a review. Antonie Van. Leeuwenhoek 81, 271-282 (2002).

27. Valenzuela, E. I. et al. Anaerobic methane oxidation driven by microbial reduction of natural organic matter in a tropical wetland. Appl. Environ. Microbiol. 83, e00645-00617 (2017).

28. Chanton, J. P. The effect of gas transport on the isotope signature of methane in wetlands. Org. Geochem. 36, 753-768 (2005).

29. Zeikus, J. \& Henning, D. L. Methanobacterium arbophilicum sp. nov. An obligate anaerobe isolated from wetwood of living trees. Antonie van. Leeuwenhoek 41, 543-552 (1975).

30. Yip, D. Z., Veach, A. M., Yang, Z. K., Cregger, M. A. \& Schadt, C. W. Methanogenic Archaea dominate mature heartwood habitats of Eastern Cottonwood (Populus deltoides). N. Phytologist 222, 115-121 (2019).
31. Schink, B., Ward, J. C. \& Zeikus, J. G. Microbiology of wetwood: importance of pectin degradation and Clostridium species in living trees. Appl. Environ. Microbiol. 42, 526-532 (1981)

32. Flanagan, L. B. et al. Multiple processes contribute to methane emission in a riparian cottonwood forest ecosystem. N. Phytologist 229, 1970-1982 (2021).

33. Maher, D. T., Cowley, K., Santos, I. R., Macklin, P. \& Eyre, B. D. Methane and carbon dioxide dynamics in a subtropical estuary over a diel cycle: insights from automated in situ radioactive and stable isotope measurements. Mar. Chem. 168, 69-79 (2015)

34. Jeffrey, L. C., Maher, D. T., Tait, D. R. \& Johnston, S. G. A small nimble in situ fine-scale flux method for measuring tree stem greenhouse gas emissions and processes (SNIFF). Ecosystems, 23, 1676-1689 (2020).

35. Vicca, S., Flessa, H., Loftfield, N. \& Janssens, I. The inhibitory effect of difluoromethane on $\mathrm{CH} 4$ oxidation in reconstructed peat columns and sideeffects on CO2 and N2O emissions at two water levels. Soil Biol. Biochem. 41, 1117-1123 (2009).

36. Miller, L. G., Sasson, C. \& Oremland, R. S. Difluoromethane, a new and improved inhibitor of methanotrophy. Appl. Environ. Microbiol. 64, 4357-4362 (1998).

37. Chiri, E. et al. Termite mounds contain soil-derived methanotroph communities kinetically adapted to elevated methane concentrations. ISME J. 14, 2715-2731 (2020).

38. Kip, N. et al. Ultra-deep pyrosequencing of pmoA amplicons confirms the prevalence of Methylomonas and Methylocystis in Sphagnum mosses from a Dutch peat bog. Environ. Microbiol. Rep. 3, 667-673 (2011).

39. Tyler, S. C., Crill, P. M. \& Brailsford, G. W. 13C12C fractionation of methane during oxidation in a temperate forested soil. Geochimica et. Cosmochimica Acta 58, 1625-1633 (1994).

40. Snover, A. K. \& Quay, P. D. Hydrogen and carbon kinetic isotope effects during soil uptake of atmospheric methane. Glob. Biogeochem. Cycles 14, 25-39 (2000)

41. Teh, Y. A., Silver, W. L. \& Conrad, M. E. Oxygen effects on methane production and oxidation in humid tropical forest soils. Glob. Change Biol. 11, 1283-1297 (2005).

42. Happell, J. D., Chanton, J. P. \& Showers, W. S. The influence of methane oxidation on the stable isotopic composition of methane emitted from Florida swamp forests. Geochimica et. Cosmochimica Acta 58, 4377-4388 (1994).

43. Zhang, G., Yu, H., Fan, X., Ma, J. \& Xu, H. Carbon isotope fractionation reveals distinct process of $\mathrm{CH} 4$ emission from different compartments of paddy ecosystem. Sci. Rep. 6, 1-10 (2016)

44. Zhang, G. et al. Pathway of $\mathrm{CH} 4$ production, fraction of $\mathrm{CH} 4$ oxidized, and $13 \mathrm{C}$ isotope fractionation in a straw-incorporated rice field. Biogeosciences $\mathbf{1 0}$ 3375-3389 (2013)

45. Templeton, A. S., Chu, K.-H., Alvarez-Cohen, L. \& Conrad, M. E. Variable carbon isotope fractionation expressed by aerobic $\mathrm{CH} 4$-oxidizing bacteria. Geochimica et. Cosmochimica Acta 70, 1739-1752 (2006).

46. Yun, J., Yu, Z., Li, K. \& Zhang, H. Diversity, abundance and vertical distribution of methane-oxidizing bacteria (methanotrophs) in the sediments of the Xianghai wetland, Songnen Plain, northeast China. J. Soils Sediment. 13, 242-252 (2013).

47. Kip, N. et al. Detection, isolation, and characterization of acidophilic methanotrophs from Sphagnum mosses. Appl. Environ. Microbiol. 77, 5643-5654 (2011).

48. Carere, C. R. et al. Mixotrophy drives niche expansion of verrucomicrobial methanotrophs. ISME J. 11, 2599-2610 (2017).

49. Pol, A. et al. Methanotrophy below $\mathrm{pH} 1$ by a new Verrucomicrobia species Nature 450, 874-878 (2007)

50. van Teeseling, M. C. et al. Expanding the verrucomicrobial methanotrophic world: description of three novel species of Methylacidimicrobium gen. nov. Appl. Environ. Microbiol. 80, 6782-6791 (2014).

51. Chan, A. \& Parkin, T. Evaluation of potential inhibitors of methanogenesis and methane oxidation in a landfill cover soil. Soil Biol. Biochem. 32, 1581-1590 (2000)

52. Urmann, K., Schroth, M. H. \& Zeyer, J. Recovery of in-situ methanotrophic activity following acetylene inhibition. Biogeochemistry 89, 347-355 (2008).

53. Nauer, P. A., Hutley, L. B. \& Arndt, S. K. Termite mounds mitigate half of termite methane emissions. Proc. Natl Acad. Sci. USA 115, 13306-13311 (2018).

54. Coleman, D. D., Risatti, J. B. \& Schoell, M. Fractionation of carbon and hydrogen isotopes by methane-oxidizing bacteria. Geochimica et. Cosmochimica Acta 45, 1033-1037 (1981).

55. Holmes, A. J., Costello, A., Lidstrom, M. E. \& Murrell, J. C. Evidence that participate methane monooxygenase and ammonia monooxygenase may be evolutionarily related. FEMS Microbiol. Lett. 132, 203-208 (1995).

56. Costello, A. M. \& Lidstrom, M. E. Molecular characterization of functional and phylogenetic genes from natural populations of methanotrophs in lake sediments. Appl. Environ. Microbiol. 65, 5066-5074 (1999). 
57. Henneberger, R. et al. Field-scale tracking of active methane-oxidizing communities in a landfill cover soil reveals spatial and seasonal variability. Environ. Microbiol. 17, 1721-1737 (2015).

58. Caporaso, J. G. et al. Global patterns of $16 \mathrm{~S}$ rRNA diversity at a depth of millions of sequences per sample. Proc. Natl Acad. Sci. USA 108, 4516-4522 (2011).

59. Apprill, A., McNally, S., Parsons, R. \& Weber, L. Minor revision to V4 region SSU rRNA 806R gene primer greatly increases detection of SAR11 bacterioplankton. Aquat. Microb. Ecol. 75, 129-137 (2015).

60. Bolyen, E. et al. Reproducible, interactive, scalable and extensible microbiome data science using QIIME 2. Nat. Biotechnol. 37, 852-857 (2019).

61. Parks, D. H. et al. A standardized bacterial taxonomy based on genome phylogeny substantially revises the tree of life. Nat. Biotechnol. 36, 996-1004 (2018).

62. Chiri, E., Nauer, P. A., Rainer, E.-M., Zeyer, J. \& Schroth, M. H. High temporal and spatial variability of atmospheric-methane oxidation in Alpine glacier forefield soils. Appl. Environ. Microbiol. 83, 1-16 (2017).

63. Callahan, B. J. et al. DADA2: high-resolution sample inference from Illumina amplicon data. Nat. Methods 13, 581-583 (2016)

64. Wen, X., Yang, S. \& Liebner, S. Evaluation and update of cutoff values for methanotrophic pmoA gene sequences. Arch. Microbiol. 198, 629-636 (2016).

65. McMurdie, P. J. \& Holmes, S. phyloseq: an R package for reproducible interactive analysis and graphics of microbiome census data. PloS ONE $\mathbf{8}$, e61217 (2013).

66. Anderson, M. J., Ellingsen, K. E. \& McArdle, B. H. Multivariate dispersion as a measure of beta diversity. Ecol. Lett. 9, 683-693 (2006).

67. Bureau of Meteorology. Data retreived 26th January $2021 \mathrm{http}: / /$ www.bom. gov.au/climate/dwo/IDCJDW4036.latest.shtml

\section{Acknowledgements}

This work was supported by funding from the Australian Research Council (LP160100061 and DP210100096). We thank Roz Hagan for lab assistance, Caroline Einig for preliminary testing, Joseph Hall, Leo and Naomi Jeffrey for field assistance and Thanavit Jirapanjawat for help with DNA extractions and qPCR. We also thank Huub Op den Camp for their helpful comments. L.C.J and D.R.T acknowledge support from the Australian Research Council that partially funds their salaries (LP160100061 and DE180100535 respectively). C.G. acknowledges salary support from the National Health \& Medical Research Council (APP1178715) and consumables support from the Australian Research Council (DP180101762). S.K.A. and P.A.N. are grateful for financial contributions from the University of Melbourne Research Grant Support Scheme, and P.A.N. for salary contributions from the Australian Research Council (DP180101762; awarded to CG). Supplementary information is available for this paper.

\section{Author contributions}

S.G.J., D.T.M. and L.C.J. conceived the study. L.C.J. and D.R.T. conducted the DFM fieldwork with guidance from P.A.N. L.C.J. collected bark samples and conducted incubation experiments with guidance from D.T.M. and S.G.J. E.C., C.G. and P.M.L. designed and conducted microbial community analysis. L.C.J., S.G.J., D.T.M., C.G. and E.C. wrote the manuscript. L.C.J., D.T.M., E.C., P.M.L., P.A.N., S.K.A., D.R.T., C.G. and S.G.J. edited and approved the manuscript.

\section{Competing interests}

The authors declare no competing interests

\section{Additional information}

Supplementary information The online version contains supplementary material available at https://doi.org/10.1038/s41467-021-22333-7.

Correspondence and requests for materials should be addressed to L.C.J.

Peer review information Nature Communications thanks Paul Brewer, Marina Kalyuzhnaya, and Jorge Villa for their contributions to the peer review of this work. Peer review reports are available.

Reprints and permission information is available at http://www.nature.com/reprints

Publisher's note Springer Nature remains neutral with regard to jurisdictional claims in published maps and institutional affiliations. Attribution 4.0 International License, which permits use, sharing, adaptation, distribution and reproduction in any medium or format, as long as you give appropriate credit to the original author(s) and the source, provide a link to the Creative Commons license, and indicate if changes were made. The images or other third party material in this article are included in the article's Creative Commons license, unless indicated otherwise in a credit line to the material. If material is not included in the article's Creative Commons license and your intended use is not permitted by statutory regulation or exceeds the permitted use, you will need to obtain permission directly from the copyright holder. To view a copy of this license, visit http://creativecommons.org/ licenses/by/4.0/.

(C) The Author(s) 2021 